\title{
Spatial association between murres (Uria spp.), puffins (Fratercula spp.) and fish shoals near Pribilof Islands, Alaska
}

\author{
Gordon Swartzman ${ }^{1, *}$, George Hunt ${ }^{2}$ \\ ${ }^{1}$ Applied Physics Laboratory 355640, University of Washington, Seattle, Washington 98195, USA \\ ${ }^{2}$ Department of Ecology and Evolutionary Biology, University of California, Irvine, California 92697, USA
}

\begin{abstract}
Feeding by piscivorous marine seabirds necessitates some spatial association between them and their prey. Many attempts have been made to establish spatial associations between seabirds and their prey, yet small-scale $(<1 \mathrm{~km})$ proximate association is rarely found. In this paper, we review past attempts to examine spatial proximity, and provide yet another attempt which introduces the concept of a feeding cluster or association of birds. We show, using data collected on acoustic surveys in the neighborhood of the Pribilof Islands, Alaska, during September 1994 to 1997, that larger clusters (>10 birds) of piscivorous murres (Uria spp.) and puffins (Fratercula spp.) are consistently associated with their major prey in this area, large shoals of Age-0 pollock Theragra chalcogramma. Furthermore, the number of birds in a bird cluster is usually proportional to the biomass of fish under that cluster.
\end{abstract}

KEY WORDS: Spatial association · Bird clusters

\section{INTRODUCTION}

If predators are to be successful in capturing prey, there must be at least an occasional, close spatial association between the predator and its prey. Documentation of this spatial association between seabirds and their prey has proven elusive. In this paper we explore new methods for quantifying spatial relationships between abundance of piscivorous sea birds and their prey, and apply them to the results of predator-prey studies conducted in the vicinity of the Pribilof Islands, Alaska (Fig. 1).

The strength of the spatial and numerical relationships between seabirds and their prey is scale-dependent (Schneider \& Piatt 1986, Hunt \& Schneider 1987, Schneider 1990, 1993, 1994, Logerwell et al. 1998, O'Driscoll 1998). That is, the results obtained are dependent on both the resolution and the extent of the

*E-mail: gordie@apl.washington.edu study. Most studies have sought correlations between the abundance of seabirds and their prey along transects 10s to 100s of kilometers in length. In this paper we define a scale-free measure of bird-fish spatial relationship, the bird cluster, defined as segments of the study transects over which all birds are within a threshold distance of each other. We contrast the use of measures of spatial overlap between piscivorous birds and their prey based on these bird spatial clusters with correlation-based methods based on an arbitrary spatial resolution or bin size (e.g. spectral analysis).

Arbitrary binning of data into transect segments varying in length from $100 \mathrm{~m}$ to $\geq 10 \mathrm{~km}$ has revealed stronger correlations between birds and their prey at larger $(>3 \mathrm{~km})$ measurement intervals (Hunt et al. 1992, 1999). Similarly, analytical methods that are multi-scale (spectral analysis, wavelet analysis, scaledependent correlation) have confirmed the scaledependency of the relationships between seabirds and their prey, with maximum coherence, correlation and wavelet variances at scales of $600 \mathrm{~m}$ to $10 \mathrm{~km}$ (Schnei- 


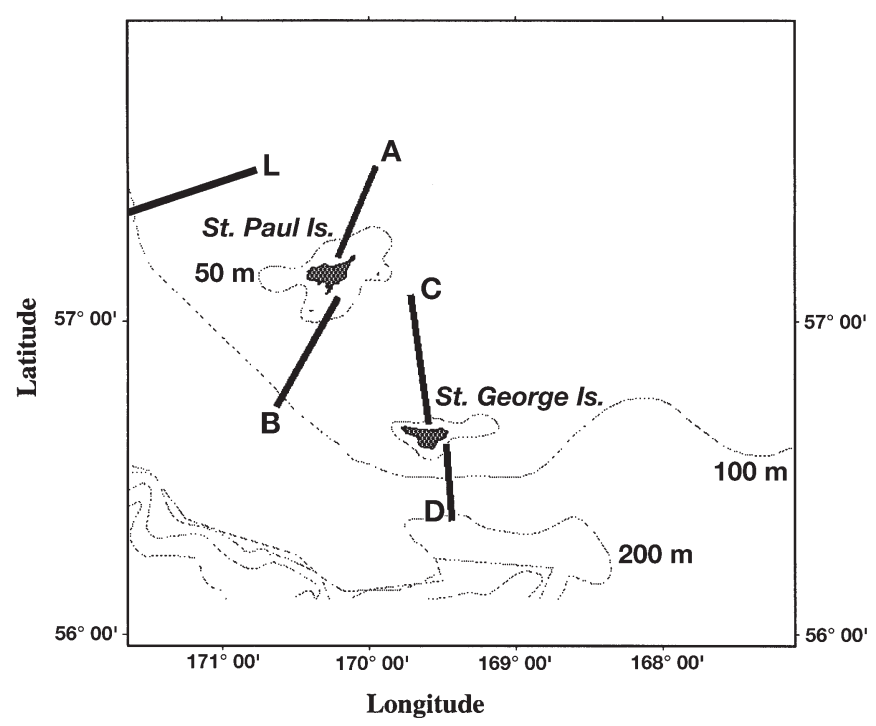

Fig. 1. Map of study area, showing location of the Pribilof Islands, Transects A-D and L, and 100 and $200 \mathrm{~m}$ isobaths

der \& Piatt 1986, Logerwell et al. 1998, Mehlum et al. 1996). Only when seabirds are foraging on prey at the water's surface, or when there are strong surface indicators of physical mechanisms that are concentrating prey, is there strong small-scale coincidence of seabirds and their prey (e.g. Brown 1980, Safina \& Burger 1985, 1989, Decker 1995, Goss et al. 1997).

In past studies of the distribution of seabirds with respect to prey, the prey biomass as well as the predator numbers were binned. We replace this by an algorithm that locates the actual spatial extent of fish aggregations, shoals or patches. To do this we developed an algorithm for the automated identification of prey patches along a series of transects in the vicinity of the Pribilof Islands, Alaska (Swartzman et al. 1999). This method also eliminated small targets, such as individual fish, thus focusing on birds feeding on fish shoals.

\section{MATERIALS AND METHODS}

Acoustic surveys were conducted in mid-September 1994 to 1997 aboard the NOAA ship 'Miller Freeman'. Acoustic data were collected using SIMRAD EK500 echo sounder systems, centerboard mounted, and recording at 38 and $120 \mathrm{kHz}$. All transducers were calibrated prior to each cruise by the standard sphere method (Foote et al. 1987). The ping data were subsampled to provide backscatter images of 1000 pixels horizontal per $8 \mathrm{~km}$ (or $8 \mathrm{~m}$ horizontal resolution), with $0.5 \mathrm{~m}$ vertical resolution. Here we include data from Transects A to D (all years) and L (1994 and 1995 only), near St. Paul Island and St. George Island (Fig. 1). The transects were between 17 and $30 \mathrm{n}$ miles in length.

Fish species and size composition were sampled both on targets and at preselected locations along the transects using anchovy and Methot trawls (Brodeur et al. 1997). Walleye pollock Theragra chalcogramma juveniles dominate the fish biomass in the pelagic zone, comprising $>95 \%$ of the fish biomass. Seabirds were recorded along the transects by a trained observer (Logerwell et al. 1998, M. B. Decker unpubl. data) using strip-transect methods, recording all birds sighted within $300 \mathrm{~m}$ of the vessel. Only birds on the water are included in this analysis, because this is the only recorded category that includes feeding birds.

Acoustic data images $(1000 \times 500$ pixels $)$ were 'cleaned' using bottom and near-surface bubble-layer cleaning algorithms (Swartzman et al. 1994). Fish shoals were identified using the $38 \mathrm{kHz}$ echograms. A lower threshold filter of $-53 \mathrm{~dB}$ was applied to the cleaned images. This eliminated all pixels with lower $S_{V}$ (volume backscatter), leaving only pixels expected to be in the range of backscatter target strength for the size range of pollock sampled. For juvenile pollock in the 30 to $80 \mathrm{~mm}$ total length range, Brodeur \& Wilson (1996) and Traynor (1996) found target strengths from -53 to $-37 \mathrm{~dB}$. While the acoustic backscatter in any pixel containing fish depends both on the target strength and density of fish we used the target-strength range-threshold for juvenile pollock as a surrogate for the threshold of $S_{V}$. Under this assumption we included as potentially pollock any pixels having greater than $-53 \mathrm{~dB}$ backscatter, equivalent to $30 \mathrm{~mm}$ fish at a density of 1 per cubic meter. A morphological image-processing binary filter with a $3 \times 2$ pixel (horizontal by vertical) structuring element was then applied using a binary closing followed by an opening operation (Haralick \& Shapiro 1992). The $3 \times 2$ pixel structuring element is large enough to ensure that, with the morphological filters used, small targets (e.g. individual fish) were eliminated, leaving only fish shoals. This filtered image was then multiplied by the original image, producing an image with only identified shoals but with pixel values from the original image, thereby assuring no alteration in average volume backscatter $\left(S_{V}\right)$ or in backscatter variance within the shoals (Swartzman et al. 1994). A connected component algorithm (Haralick \& Shapiro 1992) was used to extract a table from the processed image describing the identified shoals. Each shoal was characterized by its location, its area, its average volume backscatter, its depth, and its horizontal extent. A fish biomass-index (denoted as biomass) was calculated as average shoal-volume backscatter $\times$ area. $^{1}$ 
Spectral analysis provides a multi-scale means for examining correlation between species. For example, spatial correlation between murre (Uria spp.) and fish abundance was examined using spectral analysis cross-periodogram methods with a minimum bin size (highest spatial resolution) of $370 \mathrm{~m}$ (Logerwell et al. 1998). The cross-periodogram transformed the murre numbers and fish biomass spatial association into the frequency domain. The coherence, a parameter normalized to be between 0 and 1, gives a measure of the correlation between the 2 variables as a function of frequency. The phase, also a function of frequency, has a value of 0 when the 2 variables are 'in phase'. Having high coherence, with a phase close to zero over a range of frequency, suggests that there is a positive association between the variables at the spatial scale associated with that frequency. The frequency is inversely proportional to the spatial scale.

An alternative to scale-specific Eulerian methods, such as spectral and correlation analysis for looking at bird-fish spatial overlap, is to examine clusters of birds on the water and fish below the clusters. The clusters, being variable-scale, are more similar to a Lagrangian coordinate system that moves along with the system than an Eulerian reference frame. It has often been observed that marine birds are not solitary feeders, but tend to feed in clusters or aggregations (Hoffman et al. 1981, Hunt et al. 1992). We used, as an operational definition, that there is, in each cluster, $<1 \mathrm{~km}$ between all adjacent birds counted in the survey. By this definition, birds within a cluster may not be feeding in coordination, but are thought to be in visual contact with each other. A cluster may consist of only a single bird if it is $>1 \mathrm{~km}$ from each neighbor. Also, murre and puffin (Fratercula spp.) clusters are considered independently in this analysis (i.e. no mixed species clusters). We then computed total fish biomass below each cluster as an index to the amount of food available to piscivorous bird clusters. The fish biomass index used was the sum of shoal area (2-dimensional cross section) $\times$ average $S_{V}$ for all shoals within the horizontal extent of the bird cluster. Biomass for shoals that extended beyond the cluster was pro-rated by the fraction of their horizontal extent under the cluster.

To explore bird-fish proximity, we plotted the spatial distribution of numbers of observed murres and puffins on the water and of fish biomass along the transects. We used symbol plots with circles proportional in size to the counts and biomass of birds and fish, respectively. We examined scatterplots of bird cluster size vs fish biomass below the cluster. We then estimated, in-

${ }^{1}$ The biomass-index is in units of voltage $(\mu \mathrm{Pa})$ which, assuming an average target strength for the fish, is proportional to biomass. It is the product of $S_{V}\left(\mu \mathrm{Pa} \mathrm{m} \mathrm{m}^{-2}\right) \times$ area $\left(\mathrm{m}^{2}\right)$ dependently for each year and for murres and puffins, the probability that the fish biomass below a cluster was larger than a threshold biomass level for both large (greater than a threshold number of birds) and small bird clusters. We also modeled the bird-cluster size as a function of fish biomass below the cluster and distance from the nearest breeding colony (i.e. the closest Pribilof Island to the sighting location), using nonparametric generalized additive model regression (GAM; Hastie \& Tibshirani 1990). We hypothesized that numbers of murres, which had mostly left their colonies at the time of the surveys, would not be related to the distance from the islands, whereas numbers of puffins, which were still attending young on the islands, would be inversely related to distance from the nearest island. Each cluster in the GAM model was assumed to be the sum of smooths (a spline smoother was used) of the effect of each covariate. The dependent variable in GAM can be assumed to be distributed according to any distribution from the exponential family (which includes the binomial, normal, gamma and Poisson distributions). In our case we chose the Poisson distribution, commonly used for counts of biological objects (Diggle 1983).

\section{RESULTS}

For all years, plots of numbers of murres (Uria spp.) and puffins (Fratercula spp.) and fish biomass distribution along the study transects suggest that there were extensive shoals of fish over which neither murres nor puffins were observed in all years (Fig. 2). Murre and puffin spatial distributions, while similar on the large scale (i.e. transects with many murres also tended to have puffins), showed considerable difference in their spatial distribution within the transects. Also, murre and puffin numbers and pollock biomass spatial distributions and abundance varied considerably between years (Fig. 2). Although a perspective can be gained through examination with the human eye, it is difficult to ascertain the numerical features of the spatial relationship between these piscivorous birds and their fish prey from map plots.

Cross-covariograms between murre and fish biomass were computed for each of 3 passes of Transect A for 1995. Plots of the coherence and phase against frequency for the cross-covariograms (Fig. 3) showed no significant coherence or phase association at any frequency). This corroborates the general impression from the distribution maps (Fig. 2) that no spatial association existed in 1995 between murres and fish. Similar results were obtained using spectral analysis for other years and transects, and the remaining covariograms are not shown. 

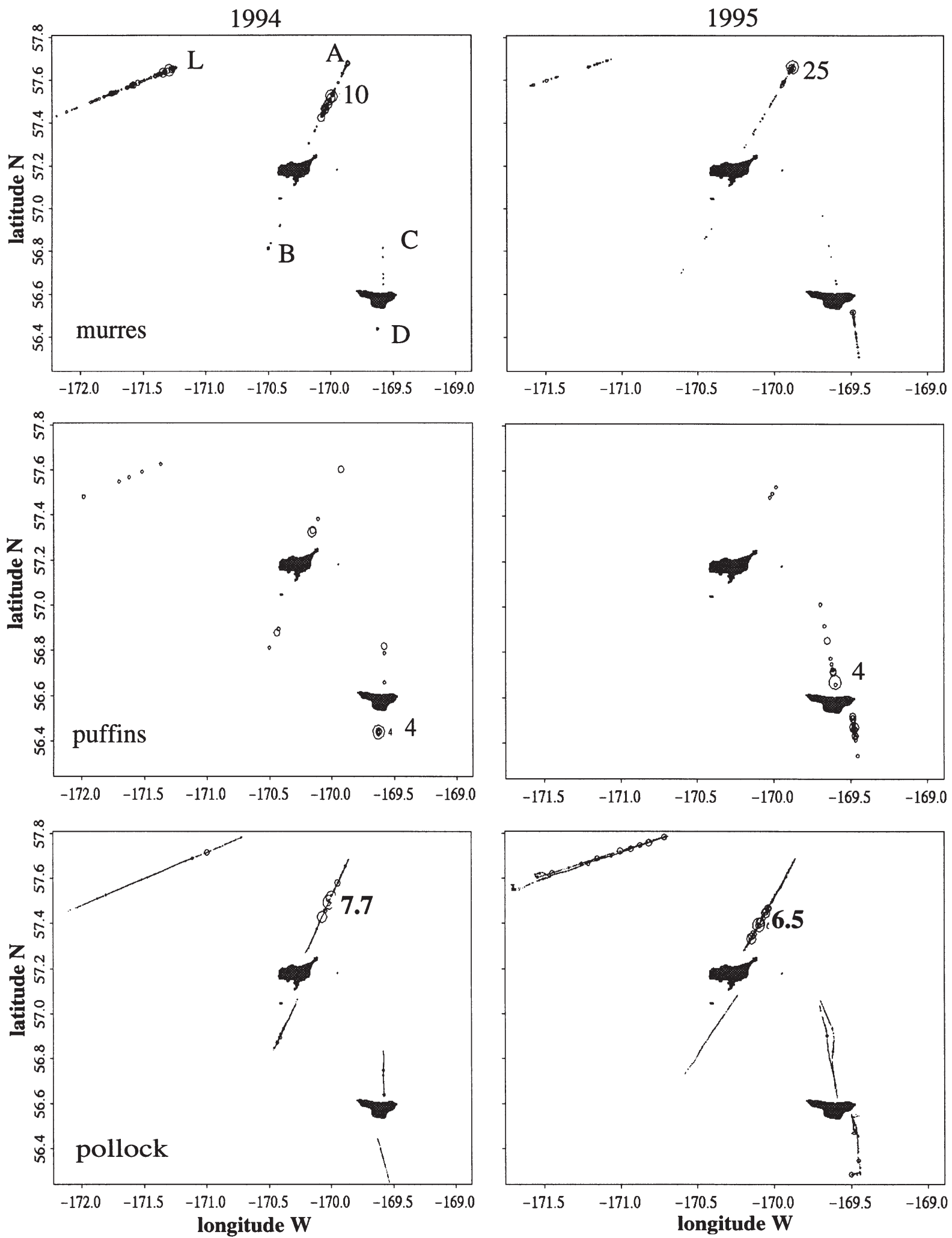

Fig. 2. Distribution of murre (Uria spp.) and puffin (Fratercula spp.) numbers and pollock biomass from acoustic surveys conducted in September 1994 to 1997 near Pribilof Islands, Alaska. Bird numbers are plotted as circles proportional in size to number of birds sighted or fish biomass estimated for each fish school acoustically sampled. Circle sizes are scaled separately for each year, with maximum value recorded next to largest circle in each panel 

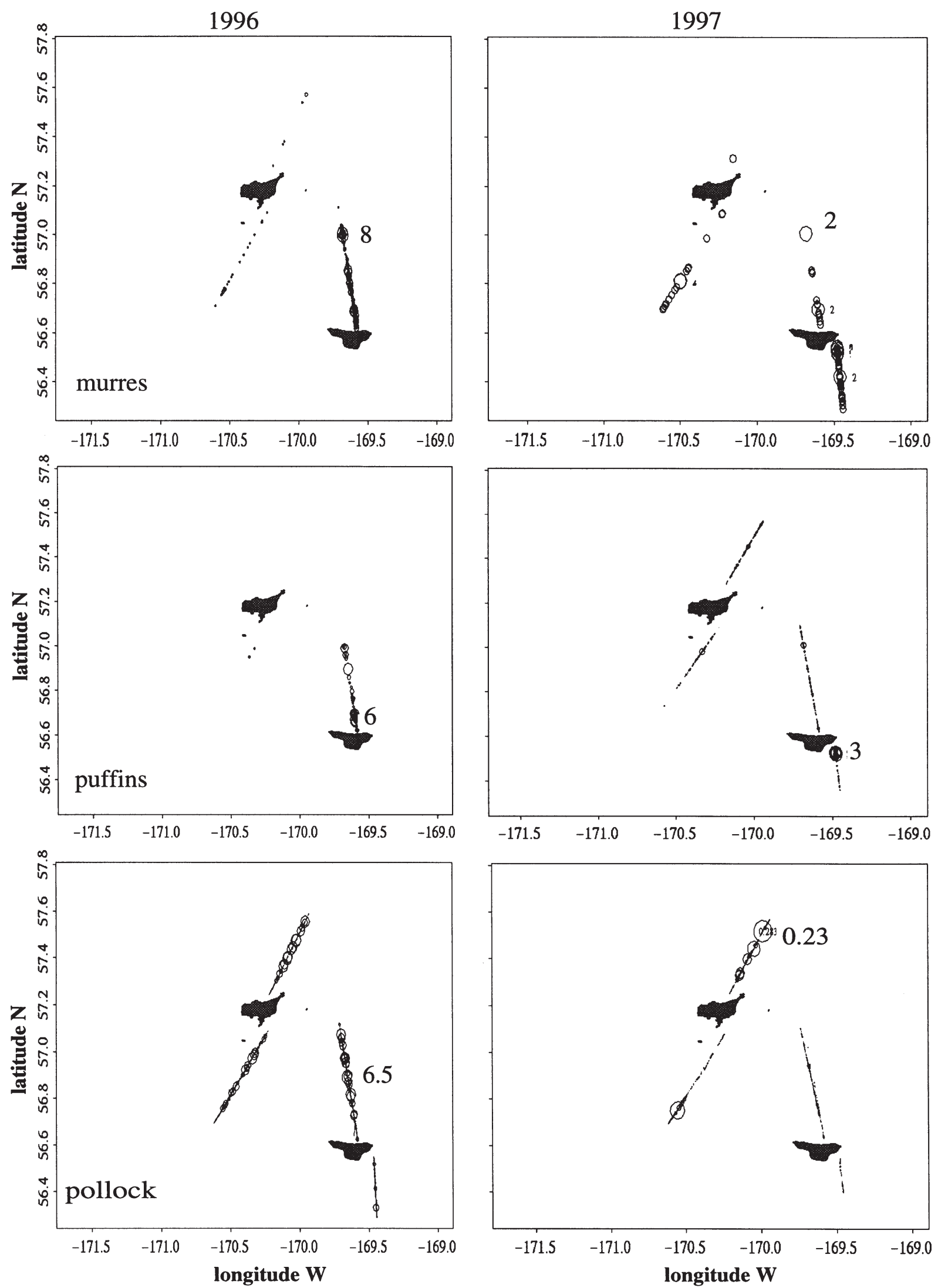

Fig. 2. (continued) 


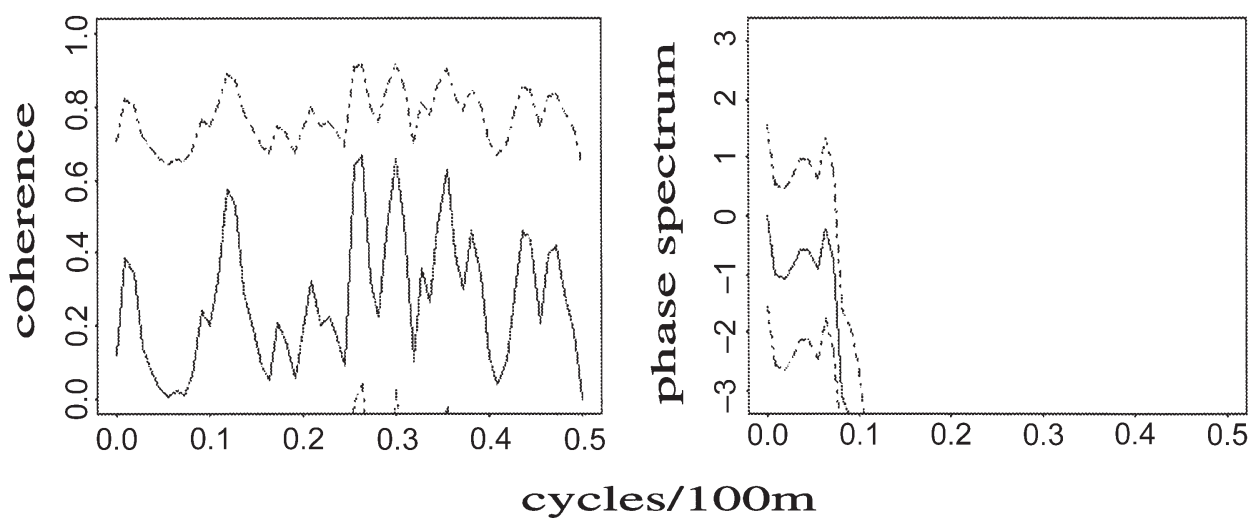

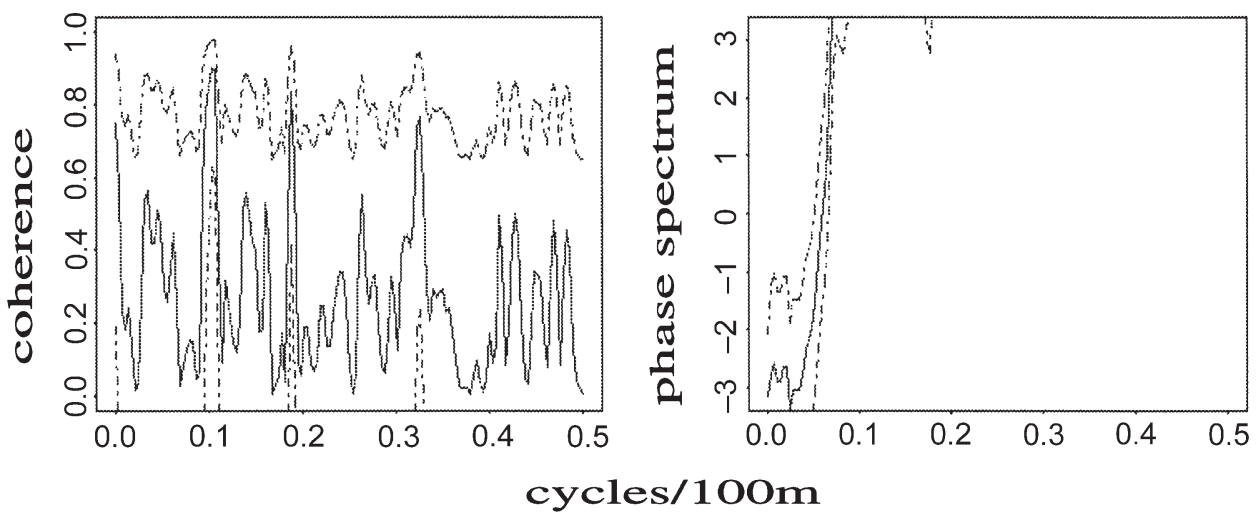

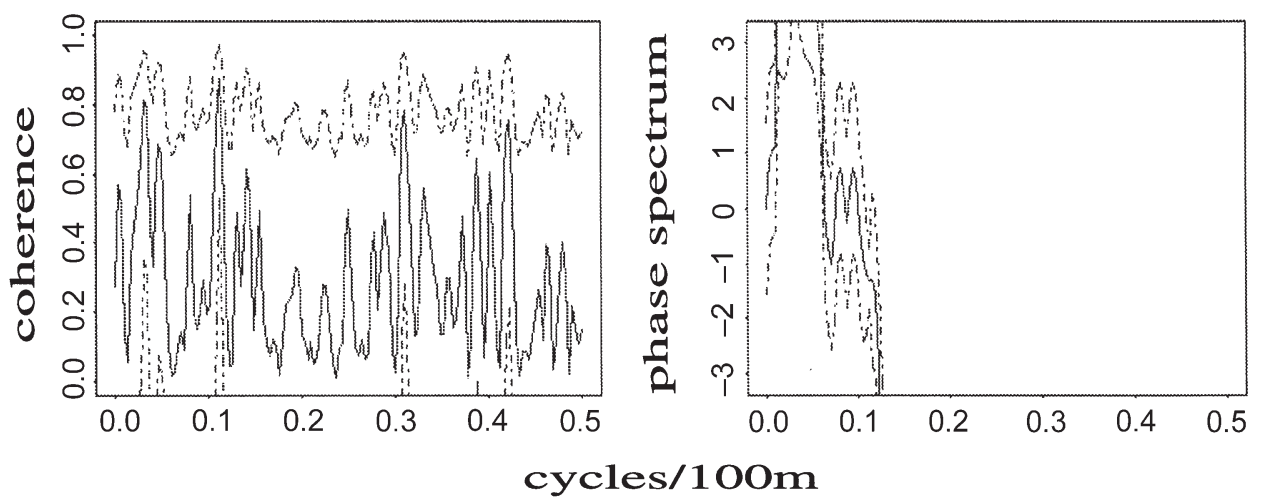

Fig. 3. Uria spp. Results of spectral analysis of horizontal spatial overlap of murre numbers and fish biomass for each of 3 daytime passes of Transect A, northeast of St. Paul Island, Alaska, in September 1995. Bin unit $=$ $100 \mathrm{~m}$. Continuous lines = coherency and phase spectrum as a function of frequency; dashed lines $=95 \%$ confidence limits. Frequency is inversely proportional to distance. Frequency of 0.5 corresponds to 2 distance units or $200 \mathrm{~m}$. High degree of overlap at some spatial scale would result in coherency close to 1.0 and phase spectrum close to zero for that frequency; no such relationship appears to exist over the distance range shown
Despite the lack of a clear spatial association between birds and fish, we hypothesize a relationship between the fish biomass below a bird aggregation and the size of the aggregation. To explore this hypothesis, we examined the relationship between the number of birds in a cluster and fish biomass below them. Scattergrams of the numbers of murres in clusters vs the biomass for pollock under each cluster for all transects for all 4 surveys from 1994 to 1997 (Fig. 4) suggest that above some murre cluster-size (numbers of birds) threshold there was a strong likelihood that fish were present below the cluster. This threshold level was 10 murres for the 1994 to 1996 surveys and
\%5 murres for the 1997 survey (Fig. 4). Results for puffins were similar (Fig. 5), although significantly fewer puffins than murres were observed and, as such, larger clusters were not as frequently encountered. Results from the scattergrams were corroborated by computing a frequency estimate of probability that the fish biomass index is $\geq 0.01$ (0.001 for 1997) for murres and puffin clusters, comprising both more (large clusters) and less (small clusters) than a threshold number of birds (Table 1).

For 1994 to 1996, with little change in bird-cluster threshold (6 to 12 birds per cluster is the range of threshold values used to separate large from small 

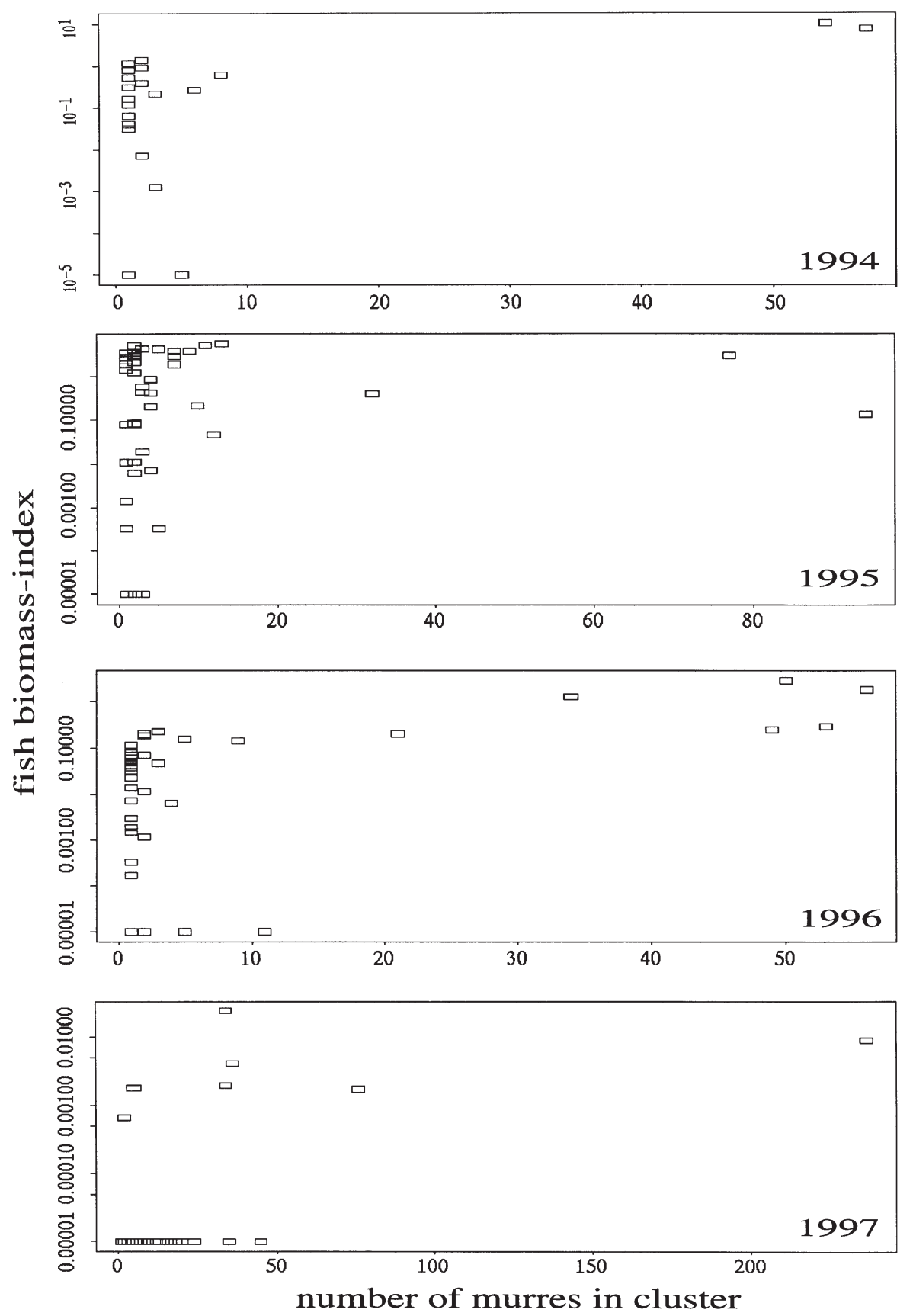

Fig. 4. Uria spp. Scattergrams of numbers of murres in a cluster vs fish biomass below cluster for survey years 1994 to 1997

Table 1. Estimate of probability that fish biomass below murre (Uria spp.) and puffin (Fratercula spp.) clusters is above a threshold (thresh) level for large (greater than bird cluster-size threshold) and small bird clusters. P: probability that fish biomass index is $>0.01$ (0.001 for 1997)

\begin{tabular}{|c|c|c|c|c|c|c|c|c|c|c|}
\hline \multirow[t]{3}{*}{ Year } & \multirow{3}{*}{$\begin{array}{l}\text { Clust. } \\
\text { thresh }\end{array}$} & \multirow{2}{*}{\multicolumn{2}{|c|}{$\begin{array}{l}\text { Murres } \\
\text { Small clusters }\end{array}$}} & \multirow{2}{*}{\multicolumn{2}{|c|}{ Large clusters }} & \multirow{3}{*}{$\begin{array}{l}\text { Clust. } \\
\text { thresh }\end{array}$} & \multirow{2}{*}{\multicolumn{2}{|c|}{$\begin{array}{l}\text { Puffins } \\
\text { Small clusters }\end{array}$}} & \multirow{2}{*}{\multicolumn{2}{|c|}{ Large clusters }} \\
\hline & & & & & & & & & & \\
\hline & & (n) & $\mathrm{P}$ & (n) & $\mathrm{P}$ & & (n) & $\mathrm{P}$ & (n) & $\mathrm{P}$ \\
\hline 1994 & 6 & (17) & 0.76 & $(4)$ & 1 & 6 & $(21)$ & 0.57 & (3) & 1 \\
\hline 1995 & 6 & (41) & 0.46 & (11) & 1 & 10 & (16) & 0.56 & (1) & 1 \\
\hline 1996 & 12 & (41) & 0.51 & (6) & 1 & 6 & (21) & 0.43 & (3) & 1 \\
\hline 1997 & 50 & (49) & $0.08(>0.001)$ & (2) & $1(>0.001)$ & 10 & $(28)$ & $0.32(>0.001)$ & (1) & $1(>0.001)$ \\
\hline
\end{tabular}




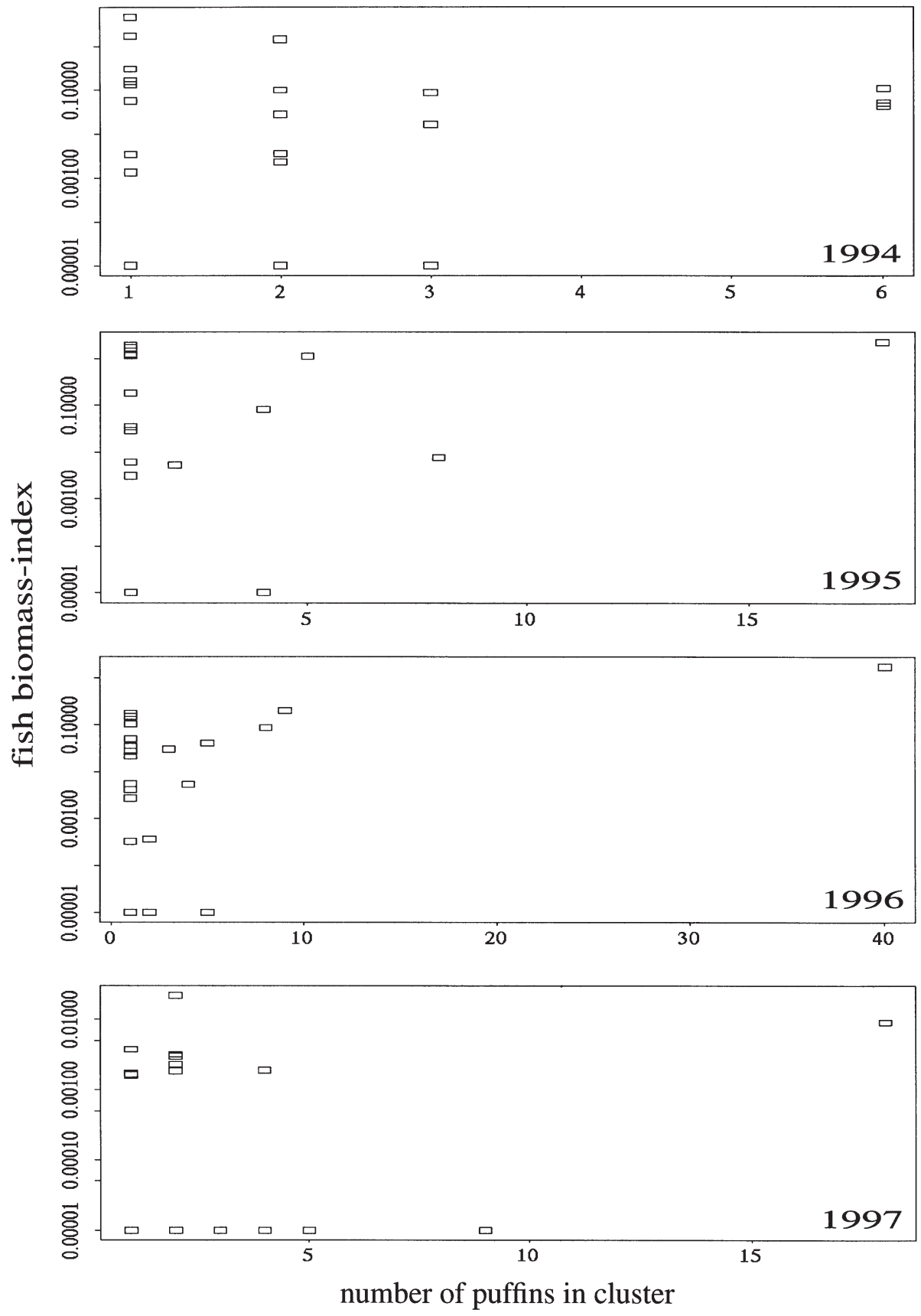

Fig. 5. Fratercula spp. Scattergrams of numbers of puffins in a cluster vs index of fish biomass below cluster for survey years 1994 to 1997

clusters for these years), all larger clusters had more than a threshold biomass (0.01) in the water column under them, while smaller clusters had $\sim 0.5$ probability of being over a biomass $>0.01$. Fish biomass was much lower in 1997 than the previous 3 yr. As such, a fish biomass threshold of 0.001 was used instead of 0.01 . In that year, only very large murre clusters $(>50$ birds) consistently had more than the threshold level of fish under them, while smaller clusters had a probability of only 0.08 (for murres) of having such levels of fish biomass under them. Sample sizes were much larger for murres than puffins and, for 2 of the 4 sample years, only 1 large puffin cluster was encountered (Table 1).

The GAM models for bird-cluster size as a function of fish biomass below the birds and distance from the nearest island for both murres (Fig. 6) and puffins (Fig. 7) suggest that piscivorous bird clusters were larger when fish abundance below them was higher. This relationship is apparent and statistically significant ( $p \leq 0.00007$ ) for murres in all years and for puffins in 1996 and 1997. However, even for these significant 


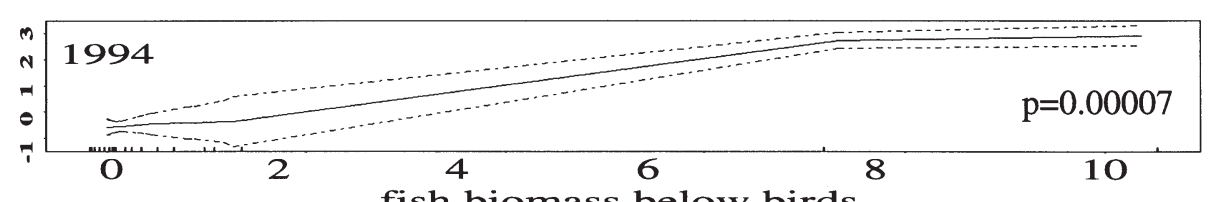

fish biomass below birds
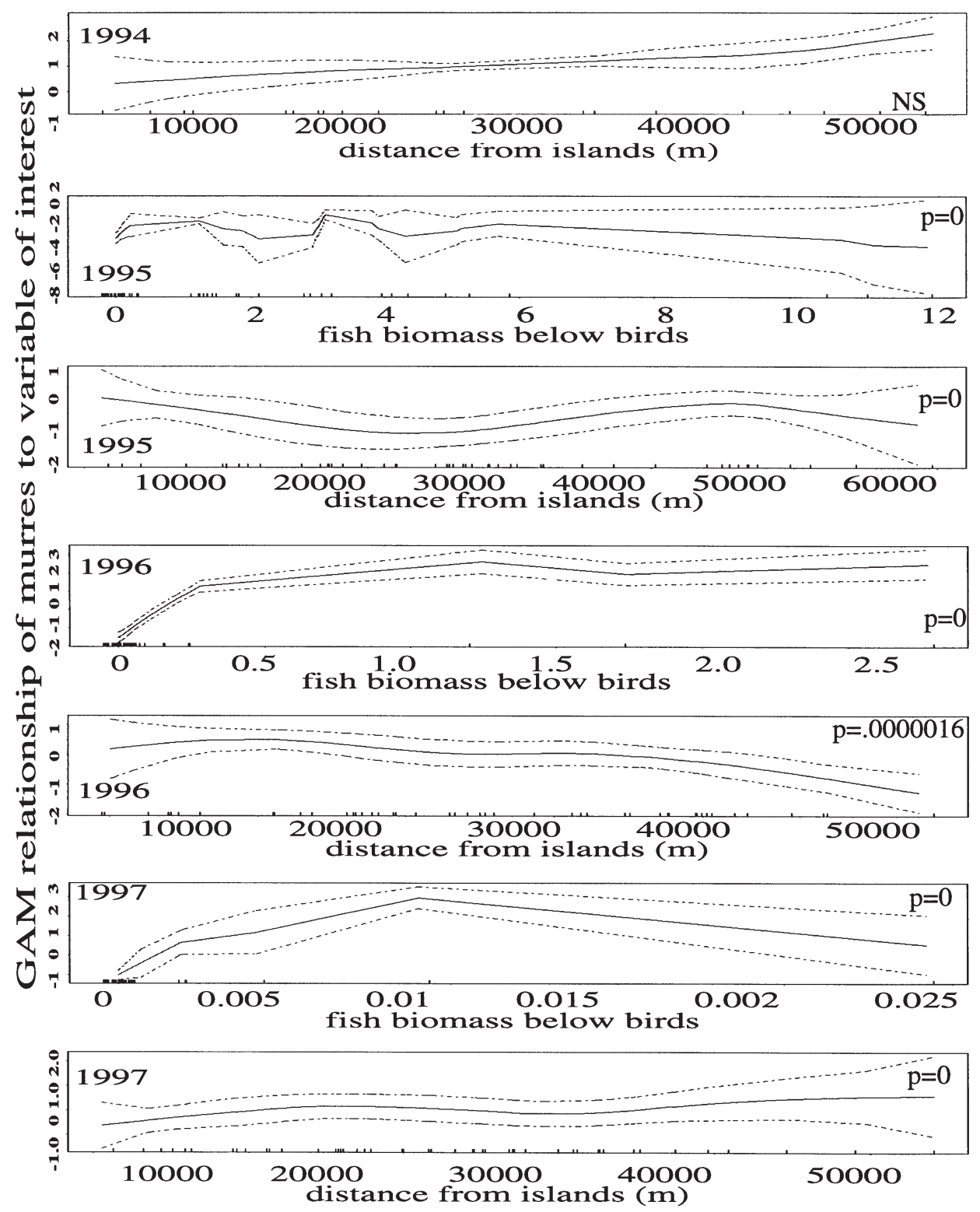

Fig. 6. Uria spp. Results of generalized additive model (GAM) nonparametric regression of numbers of murres in clusters as a function of fish biomass under clusters and distance of cluster from nearest island. Continous lines $=$ smooths of relationship of each covariate to dependent variable; dashed lines $=95 \%$ confidence limits. Significance levels (pvalues) are given on each plot. Tick marks on abscissas $=$ location of data points along $x$-axis cases, although the increase was apparent over a large fish biomass range, it did not always hold for the largest school biomass (for murres in 1995 and 1997 and puffins in 1997). This relationship appeared stronger for murres than it did for puffins (although the lack of consistency in the puffin results could be a sample-size problem). There appeared to be no consistent pattern in the effect of distance from the closest island on cluster size. In some years (1995 and 1996), murre cluster size appeared to be higher closer to the islands, while in other years $(1994,1997)$ the reverse was true. Furthermore, the effect of distance from the closest island on cluster size differed between murres and puffins.

\section{DISCUSSION}

The present study on Uria spp. and Fratercula spp. indicates that despite the lack of piscivorous bird presence over many regions of relatively high fish abun- 


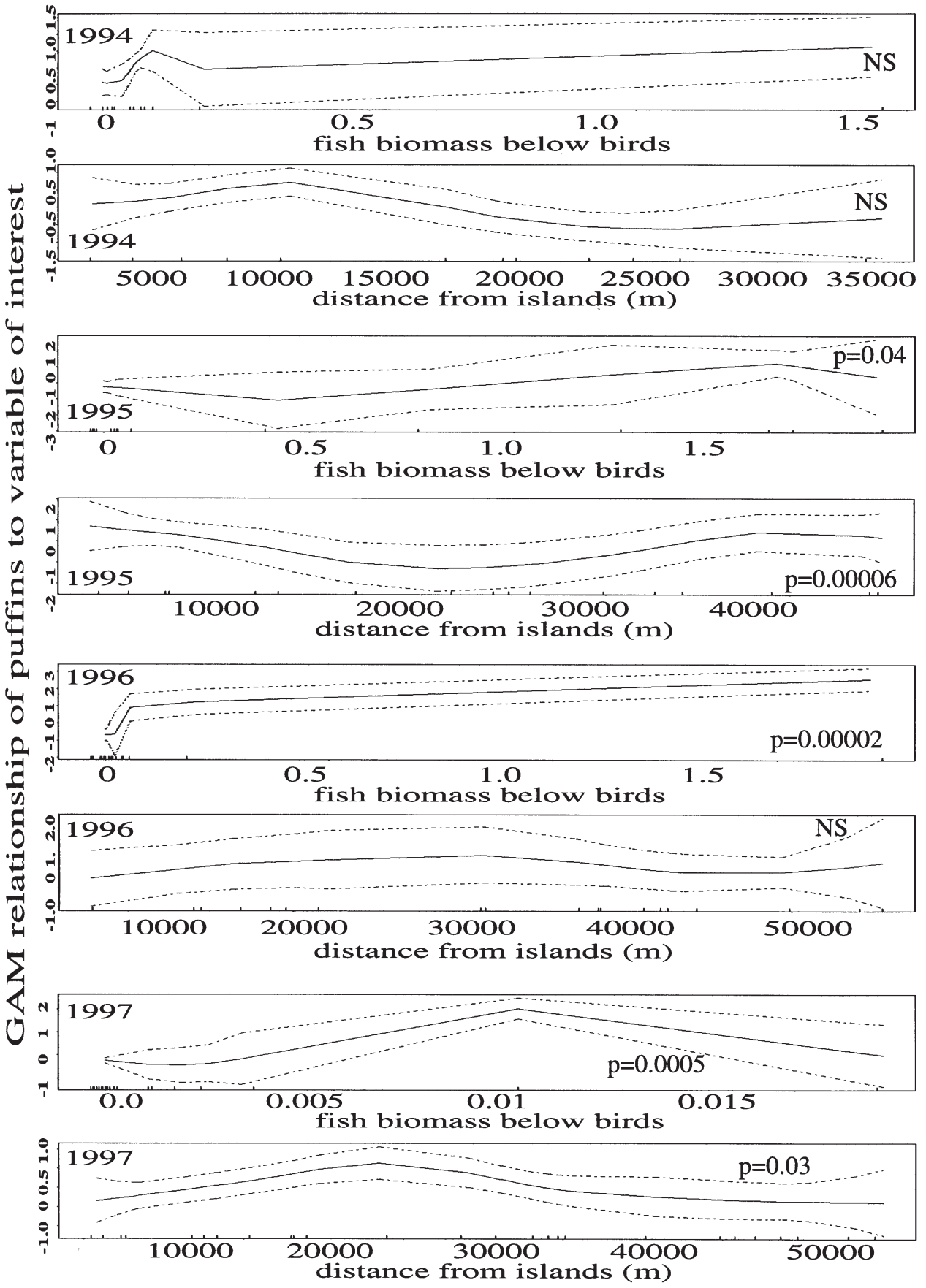

Fig. 7. Fratercula spp. Results of GAM nonparametric regression of numbers of puffins in clusters as a function of fish biomass under clusters and distance of clusters from nearest island. Details as in legend to Fig. 6

dance (Fig. 2), there appears to be considerable conditional overlap between bird clusters and fish schools under them. That is, conditional on the presence of birds on the water, there is evidence for a relationship between the number of birds in the cluster and the biomass of fish below the cluster.

Using clusters of birds to define the organization of foraging units for piscivorous seabirds provides several advantages over the binning methods used for crosscorrelation. First, the size of clusters are dependent on the resolution of the measurements and not on an arbi- trary bin size with its attendant influence on descriptive and test statistics (O'Driscoll 1998). A cluster's extent spans the spatial locations of all birds in the cluster. Second, clusters reflect the observation that many species of seabirds are patchily distributed on the ocean, and thus the clusters are natural social foraging units (Hoffman et al. 1981). Third, the use of clusters offers a means to examine hypotheses concerning the activity of birds in patches. For example, we hypothesized that above some threshold cluster-size, both murres and puffins were actively feeding, and that smaller clusters 
may be the result of social attraction during bouts of resting or other behaviors. We examined this hypothesis by looking at the relationship between bird clustersize and the biomass of fish under the cluster. We found that when $>6$ to 12 murres (50 in 1997) or puffins were present, there was always a significant amount of fish under them, whereas for smaller clusters of birds, fish were not always present.

We were unable to detect significant cross-correlations between the abundance of either murres or puffins and fish abundance along our transects at small spatial scales (between $200 \mathrm{~m}$ and 5 km; Fig. 3). Our transects were too short to allow reliable detection of correlations between the seabirds and their prey at larger spatial scales.

Not all fish shoals were being fed on by seabirds at the time of observation. Schneider \& Piatt (1986), in a study off Newfoundland, frequently encountered murres and puffins on the water with no fish under them. Obst (1985), working in the Antarctic, found that at the scale of $\sim 2 \mathrm{~km}$ the presence of large numbers of storm-petrels was a good predictor of the presence of krill, in spite of an overall lack of correlation between the abundance of these Antarctic seabirds with krill. Similarly, Heinemann et al. (1989) found for several species of Antarctic seabirds that the presence of seabirds was a better predictor for the presence of krill than was the abundance of krill a predictor of seabird numbers. The feeding behaviors of birds associated with prey may attract birds that are seeking prey, but have yet to find it (Hoffman et al. 1981, Hunt et al. 1990, Haney et al. 1992). Our observation that birds in clusters larger than a threshold are always over food suggests the hypothesis that birds on the water in these larger clusters are feeding, a hypothesis that can be tested by observation and possibly by stomach-content analysis.

Besides the possibility that the murres and puffins are not effective at finding large fish schools, at least 3 other factors may have accounted for the lack of significant cross-correlations at small scales.

One possibility is that the murres within our study area were migrants that were new to the area, and had yet to locate the prey patches. The study occurred in September, after most breeding murres had departed from the Pribilof Islands, and when murres that had bred in the northern Bering Sea were migrating south through the study area. The lack of a consistent pattern in distribution with respect to the distance to the nearest island also suggests that the majority of the murres were not breeding on the Pribilof Islands. These migrants would not have been aware of frontal features and other processes which concentrate prey (Coyle et al. 1992, Decker \& Hunt 1996). Unlike the results of these earlier studies conducted during the breeding season, in the present study murres were not associated with frontal features or tidal upwellings where prey is predictably available. However, at the time of our study, puffins were still likely to have been provisioning nestlings on the Pribilof Islands, and most puffins in the area were likely to have local knowledge. Thus, one might have expected puffins to have shown stronger associations with prey patches than they did.

A second possibility is that prey may have been sufficiently abundant within the study area and the murres and puffins sufficiently scarce to have provided no advantage to the birds in finding the areas of highest prey density. This explanation could apply to study years before 1997, but not to 1997, when prey was scarce. Letcher \& Rice (1997) modeled the circumstances under which larval fish should concentrate their foraging in patches. They found that, when overall prey densities are sufficiently great, there may be little benefit in investing the time necessary to concentrate foraging in patches. Seabirds may behave similarly. Wright \& Bailey (1993) found that seabirds that foraged on sandlance (Ammodytes marinus) near the Shetland Islands were strongly correlated with the abundance of prey in 1 year, when overall densities of sandlance were low, but in 2 years when prey were plentiful, there was no relationship between the local density of fish and the density of foraging seabirds.

A third possible explanation is that some of the fish schools were protected from bird predation by the presence of large jellyfish. Brodeur (1998) used underwater video cameras mounted on a remotely operated vehicle deployed in the study area to substantiate the widespread association of juvenile pollock with medusae tentacles. Brodeur (1998) hypothesized that this association was a protective mechanism by the fish to avoid predation. The distribution of jellyfish in sufficient abundance to deter bird predation on fish is as yet unclear, but it is plausible that foraging piscivorous seabirds would avoid such areas if other areas with fewer jellyfish were available for foraging.

Additional evidence for a relationship between birdcluster size and fish biomass came from the GAM models. These showed, in general, that where there were bird clusters, the clusters increased in size with the amount of fish biomass beneath them. The GAM relationship of increased cluster size with increased fish biomass was clearest for murres in 1994 and 1996 and for puffins in 1995 and 1996. The pattern generally held for other years as well, although in 1997, when fish biomass was low (both bird species), and in 1995 (murres) cluster size was reduced when fish biomass was highest.

Fish abundance was an order of magnitude lower in 1997 than in the previous years of the study. In addi- 
tion, in 1997, water temperatures were higher than normal and there was a massive coccolithophorid bloom that whitened the water and greatly reduced transmission of light below the surface (Vance et al. 1998). The dramatic drop in fish abundance, coupled with a reduction in sub-surface light levels, may have affected bird foraging patterns. In 1997, there was a tendency for murres to form larger clusters, as is evident in the scattergrams (Fig. 4). Furthermore, some of the larger murre clusters had no food under them in 1997 (Fig. 4). If food resources were limiting, the larger clusters may have resulted from attraction of birds from a wider area than normal. If birds remained with patches longer than usual, this could result in reduction of prey density. Data from individually tracked birds are required for testing these hypotheses. Alternatively, the murres may have formed larger patches than usual in response to the increased water turbidity in 1997 (Ericksson 1985, van Eerden \& Voslamber 1995). Van Eerden \& Voslamber suggested that cormorants in a lake in The Netherlands formed large foraging flocks as a response to increased water turbidity. The cormorants used group foraging to concentrate fish and trap them in shallow water. Neither of these behaviors were observed in our study, but we cannot rule out the possibility that decreased ability to see prey affected the tendency of the seabirds to form clumps.

Our results suggest the value of defining clustering in birds and using the clusters as natural units for examining the spatial relationships between predators and their prey. Although we used fish data based on fish school biomass, it is also possible to use horizontally binned fish-biomass estimates. However, the bin size, if too large, could lead to errors in bird cluster-fish biomass overlap. The technique for examining birdcluster fish relationships outlined in this paper needs in the future to be applied to data sets in which the density of observable predators is sufficiently high to provide clearer measures of the relationship between predators and prey.

Acknowledgements. This paper was sponsored by the NOAA Coastal Ocean Program through the Southeast Bering Sea Carrying Capacity and is contribution S383. We thank Elizabeth Logerwell and Mary Beth Decker who collected the bird data used in this paper. We also thank Jeffrey Napp and Richard Brodeur for acoustic data collection and helpful comments on the paper.

\section{LITERATAURE CITED}

Brodeur RD (1998) In situ observations of the association between juvenile fishes and Scyphomedusae in the Bering Sea. Mar Ecol Prog Ser 163:11-20

Brodeur RD, Wilson MT (1996) Mesoscale acoustic patterns of juvenile walleye pollock (Theragra chalcogramma) in the western Gulf of Alaska. Can J Fish Aquat Sci 54: 1953-1965

Brodeur RD, Wilson MT, Napp JM, Stabeno PJ, Salo S (1997) Distribution of juvenile pollock relative to frontal structure near the Pribilof Islands. Alaska Sea Grant Rep AK-SG9701:573-589

Brown RGB (1980) Seabirds as marine animals. In: Burger J, Olla BL, Winn HE (eds) Behavior of marine animals, Vol 4. Plenum Press, New York, p 1-39

Coyle KO, Hunt GL Jr, Decker MB, Weingartner TJ (1992) Murre foraging, epibenthic sound scattering and tidal advection over a shoal near St. George Island, Bering Sea. Mar Ecol Prog Ser 83:1-14

Decker MB (1995) Influences of oceanographic processes on seabird ecology. PhD thesis, University of California, Irvine

Decker MB, Hunt GL Jr (1996) Foraging by murres (Uria spp.) at tidal fronts surrounding the Pribilof Islands, Alaska, USA. Mar Ecol Prog Ser 139:1-10

Diggle P (1983) Statistical analysis of spatial point patterns. Academic Press, London

Eriksson MOG (1985) Prey detectability for fish-eating birds in relation to fish density and water transparency. Ornis Scand 16:1-7

Foote K, Knutsen H, Vestnes G, MacLennan D, Simmonds J (1987) Calibration of acoustic instruments for fish density estimation: a practical guide. ICES Co-op Res Rep 144: $1-57$

Goss C, Bone DG, Peck JM, Everson I, Hunt GL Jr, Murray AWA (1997) Small-scale interactions between prions Pachyptila spp. and their zooplankton prey at an inshore site near Bird Island, South Georgia. Mar Ecol Prog Ser 154:41-51

Haney JC, Fristrup KM, Lee DS (1992) Geometry of visual recruitment by seabirds to ephemeral foraging flocks. Ornis Scand 23:49-62

Haralick R, Shapiro L (1992) Image analysis, Vol I. AddisonWesley, New York

Hastie T, Tibshirani R (1990) Generalized additive models. Chapman \& Hall, London

Heinemann D, Hunt GL Jr, Everson I (1989) The distribution of marine avian predators and their prey, Euphausia superba, in Bransfield Strait and Southern Drake Passage, Antarctica. Mar Ecol Prog Ser 58:3-16

Hoffman W, Heinemann D, Weins JA (1981) The ecology of seabird feeding flocks in Alaska. Auk 98:437-456

Hunt GL Jr, Schneider DC (1987) Scale-dependent processes in the physical and biological environment of marine birds. In: Croxall JP (ed) Seabirds: feeding biology and role in marine ecosystems. Cambridge University Press, Cambridge, p 7-41

Hunt GL Jr, Harrison NM, Cooney RT (1990) Foraging of Least Auklets: the influence of hydrographic structure and prey abundance. Stud Avian Biol 14:7-22

Hunt GL Jr, Heinemann D, Everson I (1992) Distributions and 1 interactions of macaroni penguins, Antarctic fur seals and Antarctic krill near Bird Island, South Georgia. Mar Ecol Prog Ser 86:15-30

Hunt GL Jr, Mehlum F, Russell RW, Irons D, Decker MB, Becket PH (1999) Physical processes, prey abundance, and the foraging ecology of seabirds. In: Adams NJ, Slotow R (eds) Proceedings of 22nd International Ornithology Congress Birdlife South Africa, Durban

Letcher BH, Rice JA (1997) Prey patchiness and larval fish growth and survival: inferences from an individual-based model. Ecol Model 95:29-43 
Logerwell EA, Hewitt R, Demer DA (1998) Scale-dependent spatial variance patterns and correlations of seabirds and prey in the southeastern Bering Sea as revealed by spectral analysis. Ecography 21:212-223

Mehlum F, Hunt GL Jr, Klusek Z, Decker MB, Nordland N (1996) The importance of prey aggregations to the distribution of Brünnich's guillemots in Storfjorden, Svalbard. Polar Biol 16:537-547

Obst BS (1985) Densities of Antarctic seabirds at sea and the presence of the krill Euphausia superba. Auk 102:540-549

O'Driscoll, RL (1998) Description of spatial pattern in seabird distributions along line transects using neighbour K statistics. Mar Ecol Prog Ser 165:81-94

Safina C, Burger J (1985) Common Tern foraging: seasonal trends in prey fish densities and competition with bluefish. Ecology 66:1457-1463

Safina C, Burger J (1989) Ecological dynamics among prey fish, bluefish, and foraging Common Terns in an Atlantic coastal system. In: Burger J (ed) Seabirds and other marine vertebrates. Columbia University Press, New York, p 95-173

Schneider DC (1990) Spatial autocorrelation in marine birds. Polar Res 8:89-97

Schneider DC (1993) Scale-dependent spatial dynamics: marine birds in the Bering Sea. Biol Rev 68:579-598

Schneider DC (1994) Scale-dependent patterns and species interactions in marine necton. In: Giller S, Hildrew AG, Raffaelli DG (eds) Aquatic ecology; scale, pattern and pro-

Editorial responsibility: Otto Kinne (Editor), Oldendorf/Luhe, Germany cess. Blackwell Scientific Publications, Oxford, p 441-467 Schneider DC, Piatt JF (1986) Scale-dependent correlation of seabirds with schooling fish in a coastal ecosystem. Mar Ecol Prog Ser 32:237-246

Swartzman G, Stuetzle W, Kulman K, Wen N (1994) Modeling the distribution of fish schools in the Bering Sea: morphological school identification. Nat Res Model 8:177-194

Swartzman G, Brodeur R, Napp J, Hunt G, Demer D, Hewitt R (1999) Spatial proximity of age-0 walleye pollock (Theragra chalcogramma) to zooplankton near the Pribilof Islands, Bering Sea, Alaska. Can J Fish Aquat Sci 56:545-560

Traynor JJ (1996) Target-strength measurements of walleye pollock (Theragra chalcogramma) and Pacific whiting (Merluccius productus). ICES J Mar Sci 53:253-258

Van Eerden MR, Voslamber B (1995) Mass fishing by cormorants Phalacrocorax carbo sinensis at Lake Ijsselmeer, The Netherlands: a recent and successful adaptation to a turbid environment. Ardea 83:199-212

Vance TC, Schumacher JD, Stabeno PJ, Baier CT, WyllieEchaverria T, Tynan CT, Brodeur RD, Napp JM, Coyle, KO, Decker MB, Hunt GL Jr, Stockwell D, Whitledge TE, Jump M, Zeeman S (1998) Aquamarine waters recorded for the first time in eastern Bering Sea. EOS Trans Am Geophys Un 79:121-126

Wright PJ, Bailey MC (1993) Biology of sandeels in the vicinity of seabird colonies at Shetland. Marine Laboratory, Aberdeen (Fish Res Serv Rep 14/93)

Submitted: June 17, 1999; Accepted: February 22, 2000

Proofs received from author(s): October 16, 2000 
